\title{
Measuring Kruger visitors' place attachment to specific camps
}

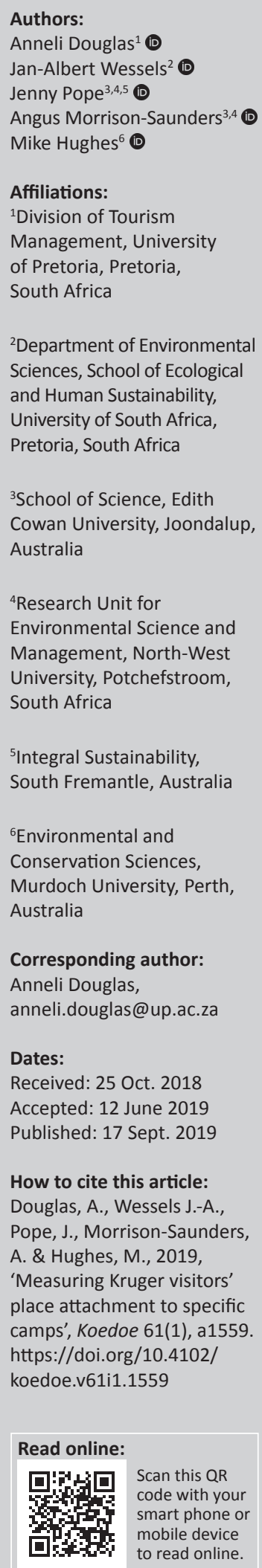

Tourists become emotionally, physically and socially attached to national parks as they become familiar with the park's settings and endow it with value. Researchers have pointed out that place attachment leads to environmentally responsible behaviour and higher levels of visitor satisfaction. Therefore, increasing the level of attachment that visitors feel is vital for park and camp managers, and to do so a greater understanding of the various dimensions of it is needed. While attachment to parks has been evaluated previously, attachment to specific camps in parks has not been done. The main purpose of this research study was to measure the extent to which visitors to the Tamboti and Satara camps in the Kruger National Park feel attached to these camps. We also determined whether differences exist between visitors in terms of the level of attachment that they experience towards these camps. Finally, we established the variables that influence place attachment. A self-administered paper-based questionnaire was distributed to visitors to the Tamboti and Satara camps, with 201 questionnaires completed. The results show that visitors generally have a neutral feeling towards the camps. Furthermore, the differences in visitors' levels of attachment could be attributed to their nationality, wild card membership and frequency of visits. Various managerial implications are drawn and recommendations made on how to increase place attachment to these camps.

Conservation implications: This results indicate that visitors do not show particularly strong attachment towards Tamboti and Satara. Recommendations are given for camp managers to increase place attachment to the camps. If camp managers can succeed in fostering stronger levels of attachment to these camps, visitors are more likely to display environmentally responsible behaviour in the camps, with positive conservation implications.

Keywords: place attachment; Kruger National Park; camps; South Africa; South African national parks.

\section{Introduction}

National Parks hold varied and often distinctive features (Reimann, Lamp \& Palang 2011) and provide the ideal setting for social and psychological exchanges to take place between people and the environment (Ramkissoon, Weiler \& Smith 2012). When these exchanges tie an individual to a park, they become attached to the park, as they familiarise themselves with the park's settings and place a value on it (Kyle, Graefe \& Manning 2005). Research into place attachment in the context of South African National Parks remains scant, even though South Africa is home to some of the most well-known national parks globally.

Place attachment helps us understand visitor behaviour (Kyle et al. 2004). Klenosky et al. (2007) state that negative place attachment occurs when specific elements of a location are in conflict with an individual's self-identity or do not satisfy an individual's needs. Negative place attachment will likely prevent an individual from visiting a location, whereas positive place attachment will encourage visitation to a location. Walker and Chapman (2003) show that positive place attachment may influence an individual's willingness to take part in protecting a place, while Vaske and Kobrin (2001) speculate that positive attachment may significantly influence environmentally beneficial behaviours (e.g. picking up litter, conserving water and recycling), especially in a nature-based context such as a national park. Previous studies have shown that tourists who are highly attached to a place will even persuade others to adopt behaviours that

Copyright: @ 2019. The Authors. Licensee: AOSIS. This work is licensed under the Creative Commons Attribution License. 
benefit the environment (Ramkissoon, Smith \& Weiler 2013a). To assist parks in fostering place attachment, a greater understanding of it is needed (Ramkissoon \& Mavondo 2014). Consequently, various calls have been made for more investigation into place attachment (Dredge 2010; Tsai 2012; Yuksel, Yuksel \& Bilim 2010).

To date, place attachment to specific national parks has been measured (Hwang, Lee \& Chen 2005; Ramkissoon et al. 2013a), but not to specific accommodation settings in these parks. The purpose of this article was thus to measure place attachment to specific camps, and not to the park in general, as this has been done before. In South African National Parks, facilities are provided at camps within parks, with these camps owned and run by the Park. It would thus make sense that visitors could become attached to a specific camp setting and that this level of attachment should be measured, rather than place attachment to the park in general. The main purpose of this study was thus to measure the extent to which visitors are attached to the Tamboti and Satara camps in the Kruger National Park. In addition, we assess whether visitors' levels of place attachment differ across age groups, nationalities, gender, level of education and others. Finally, we establish whether certain variables have a stronger influence on levels of place attachment than other variables.

The remainder of the article is structured as follows: firstly, we discuss the concepts of place, sense of place (SoP) and place attachment, after which place attachment and the dimensions thereof are clarified. Next we explain the methodology used whereafter we discuss the results. Finally, conclusions are drawn and managerial recommendations are given.

\section{Place, sense of place and place attachment}

'Place', as a concept, has both tangible and intangible dimensions; place is more than simply the location of a site. According to Halpenny (2010), the value and meaning of place are given by individuals and society, and presented in groups, cultures and individuals. Researchers are increasingly acknowledging the value of the less quantifiable and less tangible advantages that individuals get from nature and places such as protected areas (Barendse et al. 2016), for example the recreational, spiritual, experiential and educational exchanges with nature that add to the well-being of a human (Millennium Ecosystem Assessment 2005). More importantly, the extent to which one appreciates such benefits is often dependent on one's ability to engage with or form an association with the natural environment (Hinds \& Sparks 2008). Ramkissoon, Smith and Weiler (2013b) noted the overabundance of terms in the literature explaining the association between people and spatial settings, including connectedness to nature (Gosling \& Williams 2010), community attachment (Perkins \& Long 2002), place attachment (Altman \& Low 1992), SoP (Jorgensen \& Stedman 2001) and neighbourhood attachment (Lewicka 2010), among others. Authors such as Yuksel et al. (2010) opine that SoP, place identify and place dependence are forms of place attachment, whereas others such as Kyle et al. (2004b) propose that SoP is the extensive term and place attachment is a subdimension.

Chen, Dwyer and Firth (2014) explain the difference between SoP and place attachment as follows: SoP is made up of two components: relationship to place, which entails all of the various ways that people relate to places, or the kinds of ties individuals can form with a setting, and place attachment, which entails the depth and sorts of attachments to one specific place (Cross in Chen et al., 2014). Relationship to place reveals the individual-place connection in relation to how this connection is made. For example, an individual is connected to a place if he or she was born there. The relationship to place fluctuates according to the nature of the relationship rather than for psychological reasons. On the other hand, the level of attachment between a person and a place differs and may be impacted by other aspects such as memorable events, level of satisfaction and length of residence. Place attachment can reveal a person's psychological change in their connection with a specific place, and is a vital question to ask if we want to understand tourists after holidaying at a destination (Chen et al. 2014). Consequently, this study focused on the variable component of SoP: place attachment.

\section{Place attachment}

Place attachment originates from attachment theory (Bowlby 1969) and is drawing substantial attention from tourism researchers (McLeod \& Busser 2012; Ramkissoon et al. 2013b) who utilise it to discover recreationists' or tourists' attachment behaviour and feelings (Hwang et al. 2005). Williams et al. (1992) define place attachment as the emotional bond that is formed between an individual and a specific setting. Jorgensen and Stedman (2001) go further by explaining place attachment as not only an emotional bond, but also a cognitive and functional bond with a location. In recreation and leisure, Hidalgo and Hernandez (2001) are of the opinion that place attachment is personified in the feelings and emotions linked to a recreational setting. Some authors claim that when tourists become attached to tourism destinations, they display affective identification and dependence (Schultz 2000) and grow an inseparable connection with the location (Kals, Schumacher \& Montada 1999). Moore and Graefe (1994) further state that while place attachment links people with their natural environment, it also induces identification, gratification and concern for a distinctive area (Harris, Brown \& Werner 1996). Gosling and Williams (2010) have found that when people grow attached to a specific location (place), they demonstrate care and concern for the protection of the environment, and become more aware of current matters affecting the environment (Lee 2011). This then increases their commitment to the growth and conservation of natural resources (Scannell \& Gifford 2010), while at the same time leading them to exhibit environmentally responsible behaviours, such as willingly 
picking up litter (Halpenny 2006), recycling as well as conserving water (Vaske \& Kobrin 2001) and preventing environmental damage (Stedman 2002).

Cheng, Wu and Huang (2013) assert that most leisure tourism researchers assess place attachment with two constructs: place dependence, which is linked to the usefulness of a location for a leisure pastime, and place identification, which is a symbolic or emotional connection to a location (Kyle Absher \& Graefe 2003). Ramkissoon et al. (2013a) conversely see place attachment as a multidimensional construct including place affect (Kals \& Maes 2002), place dependence (Stokols \& Shumacker 1981), place social bonding (Scannell \& Gifford 2010) and place identity (Prohansky 1978), with each construct significantly different from the other (Kyle et al. 2005; Ramkissoon et al. 2012). In our study, we also view place attachment as a multidimensional construct as Ramkissoon et al. (2013a) and Devine-Wright and Clayton (2010) found that construing place attachment, as a singular concept, is rather deceptive. They emphasised the need for future research to see place attachment as a multidimensional construct, as this would aid in developing research questions that stay true to vital theoretical concepts (Stedman 2002).

These four subconstructs of place attachment - place dependence, place identity, place affect and place social bonding - are defined next.

\section{Place dependence}

According to Ramkissoon et al. (2012), national parks are theoretically the perfect setting to foster place dependence. Place dependence can be defined as how well a setting serves goal achievement given an existing range of alternatives' (Jorgensen \& Stedman 2001:234). Individuals and groups measure the functionality of places, that is, the degree to which they assist the accomplishment of specific actions. The physical characteristics of the area or destination (Williams \& Vaske 2003) personify this functional attachment and are significantly linked to the distinctive qualities that the setting is perceived to have (Williams et al. 1992). Place dependence also points to the location's relative quality when compared to other locations (Halpenny 2010). Scannell and Gifford (2010) opine that the more someone associates with the physical characteristics of a setting, the less enthusiastic he or she will be to substitute the setting for another. According to Hammitt, Backlund and Bixler (2006), place dependence is also a form of bonding, where places that gratify numerous needs generally result in a more entrenched, profound and all-encompassing place dependence, than places where fewer needs are satisfied (Stokols \& Shumaker 1981). Moore and Graefe (1994) opine that extensive interaction with a place because of place dependence may produce place identity.

\section{Place identity}

Research studies have shown that experiences with nature create place identity (Clayton \& Opotow 2003; Prohansky 1978). Place identity is defined as 'an individual's cognitions, beliefs, perceptions or thoughts that the self is invested in a particular spatial setting' (Jorgensen \& Stedman 2001:238). Place identity describes the symbolic link between a person's self-identity and his or her physical environment (Prohansky 1978:155; Stedman 2002). People usually create a sense of identity with a setting (Budruk, Thomas \& Tyrrell 2009; Halpenny 2010) because of its distinctiveness or uniqueness from other settings (Twigger-Ross \& Uzzell 1996), resulting in a psychological investment with the place as time passes (Williams \& Patterson 1999).

\section{Place affect}

Place affect mainly depends on emotions, allowing individuals to develop their feelings towards a place and giving significance to it (Tuan 1977). In the past, place affect used to be combined with place identity measures, but more recently, researchers such as Halpenny (2010) and Ramkissoon et al. (2013b) have started to regard it as a separate subdimension of place attachment. Ramkissoon et al. (2013b) show that it is likely for natural environments, such as national parks, to create feelings of psychological well-being for visitors, thus further stimulating positive emotions in visitors (Hartig et al. 1996), leading to increased levels of emotional attachment (Hinds \& Sparks 2008). Natural environments are likely to increase positive emotions (Hartig et al. 1996), leading to stronger affective connections with those environments (Hinds \& Sparks 2008; Ramkissoon et al. 2013a). Furthermore, Vining (1992) linked place affect with nature protective behaviours.

\section{Place social bonding}

Places form an essential part of social relationships. Socially based place bonds refer to the experiences individuals get from social exchanges at a specific site (Scannell \& Gifford 2010). Consequently, 'social bonding' has been developed as a dimension of place attachment, to better express the emotional and social parts of place attachment (Ramkissoon et al. 2012). As places form an essential part of social relationships, social bonding comes from the exchanges between friends and family that are reliant on a specific site (Hidalgo \& Hernandez 2001; Ramkissoon et al. 2012). According to Tonge et al. (2015), we attach meaning to a place because of the recollection of experiences in the places that we shared with our loved ones (Kyle et al. 2005), which often results in a feeling of group belonging (Low \& Altman 1992). In their assessment of social and physical place attachment, Hidalgo and Hernandez (2001) determined that the social attachments were stronger than setting attachments.

\section{How attachment levels differ based on demographics}

Research can help us in predicting the behaviour of groups and individuals in agreement with the meanings, values and feelings that they attach to a place (Cass \& Walker 2009). People's connection with nature is always a function of their value systems (Chan, Satterfield \& Goldstein 2012), which are particular to their context and constantly changing with 
time. Place attachment can vary according to certain demographical variables (Rollero \& De Piccoli 2010). According to Ednie, Daigle and Leahy (2010), the addition of sociodemographic variables is vital for research directed towards establishing management implications as it is easier to gear actions towards members of a specific sociographic group than towards those with high levels of place attachment. When considering gender, results differ. In a number of studies, men and women demonstrate similar levels of place attachment (Brown, Perkins \& Brown 2003; Ednie et al. 2010; Lewicka 2005), while in others women show stronger connections to places (Hidalgo \& Hernandez 2001; Rollero \& De Piccolli 2010). In the study of Kyle, Graefe and Manning (2004), there were significant differences between men and women, with men showing a greater place attachment than women.

Age also plays a vital role in place attachment $(\mathrm{Ng}, \mathrm{Kam} \&$ Pong 2005; Pretty, Chipuer \& Bramston 2003). Ng et al. (2005) reported a positive influence of older age on the place belonging dimension of place attachment. In their study, Kyle et al. (2004a) also found older respondents' level of attachment higher than younger respondents. Similarly, Lewicka (2008) found higher levels of attachment in older generations. This was confirmed by Ednie et al. (2010), who found a significant difference in terms of age where respondents in their low-attachment cluster were significantly younger than respondents in their highattachment cluster. The role of level of education in place attachment has not been studied sufficiently. Lewicka (2005) and Rollero and De Piccoli (2010) established that the level of education was a negative forecaster of place attachment, explaining that people with higher levels of education are more geographically moveable and thus less reliant on a specific place. Kyle et al. (2004), on the other hand, found no significant difference in terms of education, while Ednie et al. (2010) also reported no significant differences in levels of education. Furthermore, Lewicka (2008) is of the opinion that education is of less importance in predicting place attachment. In terms of travel parties, Ednie et al. (2010) reported that respondents with high place attachments were more probable to be travelling as part of a group with family and/or friends and less probable to be part of a guided group or organisation. Also, Moore and Scott (2003) found a relationship between frequency of use and positive attachment.

From the above discussion, it is clear that place attachment is made up of different dimensions, and that individuals differ in terms of their levels of attachment to a specific place. The same seems to be true in the context of South African National Parks, and Barendse et al. (2016) raised specific questions that still remain unanswered in terms of place attachment (sense of place) experiences in South African National Parks, for example, how place attachment experiences vary across groups of visitors. For this reason, we hypothesise that:

H1: Groups of visitors differ in the levels of attachment that they experience towards specific camps in the Kruger.
Another question that remains unanswered is the extent to which certain variables influence the level of place attachment that visitors experience towards specific camps. It is thus hypothesised that:

H2: Variables such as age, wild card membership, camp visited, travelling party, number of visits and gender influence the level of place attachment that visitors experience towards specific camps in the Kruger.

The methodology used to test these hypotheses is explained next.

\section{Research methods and design Study site}

The Kruger National Park (KNP) is the flagship conservation and tourism product offering within the South African National Parks system. Hausmann et al. (2017) found that visitors gave high ratings (between $4=$ perceived and $5=$ highly perceived) to the SoP dimensions in three parks, namely, KNP, iSimangaliso Wetland Park and Table Mountain National Park. Even so, research into place attachment in the context of specific camps within this park remains scarce. Some studies have been conducted in terms of SoP, with the results suggesting that although $\mathrm{SoP}$ is accounted for in national parks and environmental management, it remains an underdeveloped concept denoting a substantial void in the way that we understand the link between park management and visitor experiences (Ament et al. 2017; Barendse et al. 2016; Hausmann et al. 2017). To measure place attachment to camps, the selected camps had to comply with specific criteria. Firstly, the selected camps should have the capacity to accommodate enough visitors so that comparisons between camps could be drawn. Secondly, camps in the Southern Kruger were preferred because this would allow for the collection of more data (both the capacity and occupancy levels of camps in the southern part of the Kruger are higher than camps in the northern part of the Kruger). Thirdly, we wanted to use contrasting camps to assess if place attachment differed between the camps (the camps chosen should not only be different in name, but also in all other aspects). If similar camps were chosen, we would not have been able to attribute the differences to anything. Fourthly, we wanted to include one main camp and one satellite camp. Lastly, attachment to the camp should not be obvious. For example, given the Lower Sabie's popularity, one would assume high levels of place attachment, and thus no need to measure it. The camps that met all these criteria were Tamboti and Satara. Satara can be described as an older, more established (in the traditional KNP style) camp with permanent chalets, and ample infrastructure and facilities. On the other hand, Tamboti is a newer (more modern) camp, with rustic, semi-structured eco-tents and limited infrastructure and facilities. Satara is open to day visitors, whereas Tamboti does not allow day visitors. Interestingly, in terms of overnight guests' overall satisfaction scores with these camps (for the period May to June 2017), we see that Satara's overall satisfaction score is slightly lower than the average satisfaction score of visitors to all camps in the 
Marula region of the Kruger. In contrast, the overall satisfaction score of visitors to Tamboti is higher than the average satisfaction score of visitors to all camps in the Marula region (SANParks 2019).

\section{Questionnaire development, sampling, data collection and analysis}

A paper-based questionnaire was distributed to a convenience sample drawn from both day and overnight visitors, domestic and international, to Satara and Tamboti camps in the Kruger National Park. The questionnaires were distributed from 23 to 28 July 2017. The first section of the questionnaire asked some demographic questions, including age, gender, education level, nationality, travelling party, wild card membership and frequency of visits. The next section measured place attachment (adapted from Ramkissoon et al. 2013b). For the place attachment construct, four dimensions were included in this study: place dependence (three items), place identity (three items), place affect (three items) and place social bonding (three items). Each item was measured on a five-point Likert scale ( 1 = strongly disagree, 5 = strongly agree). Tourists were approached in both the accommodation areas as well as the public areas of the two camps. Fieldworkers were instructed to attempt to vary the age, gender and nationality of respondents. A total of 201 responses were obtained (day visitors collected at Satara $=34$; overnight in Satara $=124$; overnight in Tamboti $=43$ ).

In order to meet the purpose of the study satisfactorily, diverse techniques for data analysis were used. The descriptive methods contributed in describing the data in terms of age groups, gender representations and levels of education, while inferential methods permitted us to draw certain deductions about the larger population of travellers and their place attachment to two specific camps in the Kruger. Because of modifications necessary to customise Ramkissoon et al.'s (2013b) scale to our context, the place attachment scale was subjected to an exploratory factor analysis (EFA). T-tests and analyses of variance (ANOVAs) were used to determine how groups of visitors differ in terms of their place attachment. Lastly, multivariate analysis of variance was used to explore the effect of the key identified variables (age, camp visited, nationality, gender, wild card membership, level of education, travelling party and number of visits) as well as their possible interaction effects in explaining the variance in the two factors of place attachment. Multivariate analysis of variance (MANOVA) is a technique that is used to test for the difference in two or more vectors of means. The multivariate tests (Pillai' trace, Wilks' lambda, Hotelling's trace and Roy's largest root) all test the MANOVA null hypothesis, namely, that the mean on the composite variable is the same across groups. The test thus determines the equality of a composite of the means (optimised to yield the maximum possible F-ratio) across groups. The focus of the identification of meaningful effects will be in using Wilks' lambda in conjunction with the partial eta squared value. Although the Pillai-Bartlett criterion is considered the most robust and powerful test statistic, the Wilks' lambda is used as it provides an indication of the variance not accounted for by the combined dependent variables with $(1-\lambda)$ the variance that is accounted for by the best linear combination of dependent variables, which enables the explorative understanding of key effects.

Table 1 provides the demographic profile of the respondents. From the table, it is clear that almost an equal number of men $(48 \%)$ and women (52\%) completed the questionnaire. Almost two-thirds of respondents indicated that they are wild card members (a loyalty card that entitles members to reduced entrance fees at all national parks in South Africa). The biggest age group responding to the questionnaire were the 31-50 year-olds. Forty-five percent of respondents indicated that they hold a postgraduate degree. Nearly twothirds of respondents visited the park with family and $60 \%$ of respondents have visited the park more than three times. Official SANParks data on the gender of visitors were not available; however, in a large sample survey $(n=4369)$, conducted by the agency in 2018 on overnight visitors to the KNP, the gender split of respondents was 59\% men and $41 \%$ women. According to SANParks, however, this is not necessarily an indication of actual visitation, because the online survey that they use to collect it is sent to the email address of the person making the booking, which is dominated by men. Our sample is similar to the sample of Kruger, Viljoen and Saayman (2017). The biggest age group

TABLE 1: Demographic profiles of respondents.

\begin{tabular}{|c|c|}
\hline Demographic profile & Percentage \\
\hline \multicolumn{2}{|l|}{ Gender } \\
\hline Male & 48 \\
\hline Female & 52 \\
\hline \multicolumn{2}{|l|}{ Wild card membership } \\
\hline Yes & 64 \\
\hline No & 36 \\
\hline \multicolumn{2}{|l|}{ Age } \\
\hline $18-30$ years & 30 \\
\hline $31-50$ years & 36 \\
\hline $51-60$ years & 17 \\
\hline Older than 60 years & 17 \\
\hline \multicolumn{2}{|l|}{ Level of education } \\
\hline Secondary School or equivalent & 11 \\
\hline Post-Matric Certificate/Diploma & 23 \\
\hline Graduate & 21 \\
\hline Post Graduate & 45 \\
\hline \multicolumn{2}{|l|}{ Travelling party } \\
\hline Friends & 12 \\
\hline Family & 65 \\
\hline Friends and family & 18 \\
\hline Alone & 3 \\
\hline Special interest group & 2 \\
\hline \multicolumn{2}{|c|}{ Frequency of visits to the Kruger National Park } \\
\hline $1-3$ times & 40 \\
\hline $4-10$ times & 22 \\
\hline 11-30 times & 21 \\
\hline More than 30 times & 17 \\
\hline \multicolumn{2}{|l|}{ Nationality } \\
\hline South African & 55 \\
\hline International & 45 \\
\hline
\end{tabular}


(35\%) in their sample was between the ages of 45 and 59 years. Again, according to Kruger et al. (2017), visitors to Kruger generally hold a degree or diploma, and in our sample this was the same. In terms of frequency of visits, SANParks survey data show that $61 \%$ of their visitors have been to the Kruger for one to three times in the preceding 3 years, and $23 \%$ between four and nine times. This is similar to our sample.

\section{Ethical considerations}

Ethical approval for undertaking the research was obtained from the University of Pretoria, Faculty of Economic and Management Sciences Ethics Committee (protocol no. EMS014/17). The research was also conducted under the consent and approval of Tourism Development and Marketing Division of South African National Parks. All the participants in the study took part voluntarily after they were informed of the objectives of the study and the completion of an informed consent agreement. All participants were entitled to withdraw from the study at any point. The completed questionnaires were also completed anonymously and confidentially.

\section{Results \\ Descriptive statistics}

Visitors were asked to indicate the extent to which they agreed with a number of statements regarding the specific camps at which they were surveyed. Place attachment was measured on a five-point scale $(1=$ strongly agree and $5=$ strongly disagree). Results are shown in Table 2. It is interesting to note that visitors to the two camps did not have a particularly strong place attachment to the specific camps, even though some preferred the particular camps for their specific settings and facilities. Of the four dimensions measuring place attachment, respondents seemed to agree the strongest with the place dependence dimension, followed by place identity and place affect. Place social bonding scored the lowest mean. When compared, day visitors to Satara felt a consistent stronger attachment to the camp than overnight visitors to Satara and Tamboti. A plausible explanation could be that day visitors could include repeat visitors who come to the camp because they are attached to it, for example, people living near the KNP. Only in terms of place dependence did Tamboti visitors score higher agreement means than day and overnight visitors to Satara. The low agreement mean given to place social bonding is also interesting, especially given the fact that $95 \%$ of respondents indicated that they visit the park with friends and family. The most probable explanation could perhaps be that social bonding does not adequately explain a visitor's attachment to Tamboti and Satara.

\section{Exploratory factor analysis}

Because of the modifications necessary to customise Ramkissoon et al.'s (2013b) scale to our context (Ramkissoon et al. 2013b) measured place attachment in the context of national parks, whereas our study measured place attachment in the context of camps in the parks), the place attachment scale was subjected to an exploratory factor analysis (EFA) using maximum likelihood extraction and direct oblimin rotation (a confirmatory factor analysis was conducted first; however, model fit indicated an inadequate fit, and therefore an EFA was conducted to determine the underlying dimensional structure). The purpose of the EFA was to ensure unidimensionality and internal consistency of this construct in the present context. The Kaiser-Meyer-Olkin measure of sampling adequacy (0.908) and the Bartlett's test of sphericity which was significant $(p=0.000)$ both indicate that a factor analysis is appropriate. The EFA was conducted using a sample of 201 respondents who were intercepted at different locations in the two camps. No items were eliminated from the scale, with the number of items remaining at 12 . These 12 items used to measure the place attachment construct were loaded onto two factors (see Table 2). Based on the items, which showed that respondents would continue their attachment to specific camps, factor 1 was labelled

TABLE 2: Place attachment.

\begin{tabular}{|c|c|c|c|c|c|c|}
\hline \multirow[t]{2}{*}{ Variable } & \multicolumn{4}{|c|}{ Mean } & \multicolumn{2}{|c|}{ Factor loadings } \\
\hline & Overall & $\begin{array}{l}\text { Day visitors } \\
\text { to Satara }\end{array}$ & Satara & Tamboti & $\begin{array}{l}\text { Continued } \\
\text { attachment }\end{array}$ & $\begin{array}{l}\text { Interrupted } \\
\text { attachment }\end{array}$ \\
\hline Place dependence & 3.49 & 3.68 & 3.32 & 3.85 & - & - \\
\hline For what I like to do, I could not imagine anything better than the settings and facilities provided by this camp. & 3.69 & 3.77 & 3.54 & 4.07 & 0.754 & - \\
\hline For the activities I enjoy the most, the settings and facilities provided by this camp are the best. & 3.52 & 3.74 & 3.32 & 3.92 & 0.767 & - \\
\hline I enjoy visiting this camp and its environment more than any other camps. & 3.27 & 3.52 & 3.12 & 3.48 & 0.706 & - \\
\hline Place identity & 3.21 & 3.65 & 2.96 & 3.55 & - & - \\
\hline I identify strongly with this camp. & 3.32 & 3.71 & 3.07 & 3.70 & 0.889 & - \\
\hline I feel this camp is part of me. & 3.13 & 3.63 & 2.94 & 3.29 & 0.898 & - \\
\hline Visiting this camp says a great deal about who I am. & 3.17 & 3.61 & 2.91 & 3.59 & 0.875 & - \\
\hline Place affect & 3.17 & 3.50 & 2.99 & 3.40 & - & - \\
\hline I am very attached to this camp. & 3.15 & 3.49 & 2.99 & 3.33 & 0.893 & - \\
\hline I feel a strong sense of belonging to this camp and its settings and facilities. & 3.11 & 3.47 & 2.92 & 3.38 & 0.909 & - \\
\hline This camp means a lot to me. & 3.25 & 3.54 & 3.10 & 3.45 & 0.878 & - \\
\hline Place social bonding & 2.32 & 2.64 & 2.26 & 2.24 & - & - \\
\hline Many of my friends and family prefer this camp over many other camps. & 3.03 & 3.28 & 2.93 & 3.14 & 0.644 & - \\
\hline If I were to stop visiting this camp, I would lose contact with a number of friends. & 1.99 & 2.31 & 1.92 & 1.72 & - & 0.923 \\
\hline My friends and family would be disappointed if I were to start visiting other settings and facilities. & 1.94 & 2.32 & 1.94 & 1.86 & - & 0.930 \\
\hline
\end{tabular}


'continued attachment', while factor 2 was labelled 'interrupted attachment', because respondents indicated that if their visitation to the camp would stop, they would disappoint or lose contact with their friends and family, and hence interrupt their attachment to the specific camp. These two factors thus become composites of specific variables and include specific items that are a facet of the broader place attachment dimension (Hair et al. 2014). Internal consistency was evaluated using Cronbach's alpha and both factors showed a measurement greater than 0.9 , indicating strong levels of internal consistency (Nunnally 1978). Together, these two factors explain $75.42 \%$ of the variance.

\section{T-tests and analyses of variance}

Differences in levels of attachment between groups were measured in terms of age, the camp visited, nationality, gender, wild card membership, level of education, travelling party and number of visits. Only those where significant differences were shown in at least one of the factors are given in Table 3. From the table it is clear that South Africans have a higher level of continued attachment than international visitors have, confirming the results of Hausmann et al. (2017), who found that more experienced national tourists have a higher SoP perception. As expected, wild card members showed a stronger attachment than non-wild card members, for both factors of place attachment. Those visitors with only a matric or high school qualification had the highest levels of place attachment, followed by those with a postgraduate degree. Visitors with a matric or high school qualification felt a stronger continued attachment than visitors with a degree, while visitors with a postgraduate qualification showed a stronger continued attachment than visitors with a degree. This contradicts the results of Kyle et al. (2004) and Ednie et al. (2010) who reported no significant differences between levels of education. In terms of number of visits, those who

TABLE 3: Analysis of variance and t-tests.

\begin{tabular}{|c|c|c|c|c|c|}
\hline \multirow[t]{2}{*}{ Variable } & \multirow[t]{2}{*}{$N$} & \multicolumn{2}{|c|}{$\begin{array}{l}\text { Continued } \\
\text { attachment }\end{array}$} & \multicolumn{2}{|c|}{$\begin{array}{l}\text { Interrupted } \\
\text { attachment }\end{array}$} \\
\hline & & Mean & $p$ & Mean & $p$ \\
\hline Nationality & & & $p<0.01$ & & $p<0.17$ \\
\hline South African & 110 & 3.40 & - & 1.88 & - \\
\hline International & 91 & 3.10 & - & 2.07 & - \\
\hline Wild Card membership & & & $p<0.00$ & & $p<0.07$ \\
\hline Yes & 128 & 3.38 & - & 2.05 & - \\
\hline No & 71 & 3.01 & - & 1.80 & - \\
\hline Level of education & & & $p<0.03$ & & $p<0.25$ \\
\hline Matric/High School & 21 & $3.5^{\mathrm{a}}$ & - & 2.24 & - \\
\hline Diploma/Certificate & 46 & 3.26 & - & 1.85 & - \\
\hline Graduate & 42 & $2.93^{a, b}$ & - & 1.80 & - \\
\hline Postgraduate & 89 & $3.35^{\mathrm{b}}$ & - & 2.02 & - \\
\hline Number of visits to the Park & & & $p<0.00$ & & $p<0.47$ \\
\hline $1-3$ & 73 & $3.11^{\mathrm{a}}$ & - & 2.06 & - \\
\hline $4-20$ & 64 & $3.26^{\mathrm{b}}$ & - & 1.86 & - \\
\hline More than 20 & 46 & $3.64^{a, b}$ & - & 1.93 & - \\
\hline Camp visited & & & $p<0.00$ & & $p<0.04$ \\
\hline Day visitors to Satara & 34 & $3.58^{\mathrm{a}}$ & - & $2.31^{\mathrm{a}}$ & - \\
\hline Overnight Satara & 124 & $3.08^{\mathrm{ab}}$ & - & 1.93 & - \\
\hline Overnight Tamboti & 43 & $3.54^{\mathrm{b}}$ & - & $1.79^{\mathrm{a}}$ & - \\
\hline
\end{tabular}

have visited most frequently showed a stronger continued attachment than those who have only visited 1-3 times. At the same time, those who have visited most frequently also had a stronger attachment than those who have visited between 4 and 20 times. Interestingly, day visitors to Satara were more attached to the camp than overnight visitors to Satara. At the same time, overnight visitors to Tamboti showed a stronger continued attachment than overnight visitors to Satara. Furthermore, day visitors to Satara felt a stronger interrupted attachment to the camp than overnight visitors to Tamboti. The results thus support hypothesis 1 in that groups of visitors differ in the levels of attachment that they experience towards specific camps in the Kruger.

\section{Multivariate analysis of variance}

Multivariate analysis of variance was used to explore the effect of the key identified variables, namely, age, the camp visited, nationality, gender, wild card membership, level of education, travelling party and number of visits as well as their possible interaction effects in explaining the variance in the two factors of place attachment, namely, continued attachment and interrupted attachment. Multivariate analysis of variance has greater power to identify an effect because it can identify whether groups are different along a combination of variables, whereas ANOVA can identify only if groups are different along a single variable field. The MANOVA measures whether or not the independent grouping variable simultaneously explains a statistically significant amount of variance in the dependent variable (continued attachment and interrupted attachment). Unfortunately, the MANOVA cannot predict which groups are significantly different from each other, it only tells us that at least two groups are different and that the independent variables influence some patterning of response on the dependent variable.

The set of two dependent variables considered were not highly correlated (>0.7); thus, multi-collinearity was not present and thus were adequate for the purposes of the MANOVA analysis. The analysis revealed the following key statistical significant multivariate main and interaction effects:

- Wild card membership: Wilks' $\lambda=0.839, F=4.211, p<$. 0.021 , partial eta squared $=0.161$. Power to detect the effect was 1 .

- Camp visited: Wilks' $\lambda=0.797, F=2.639, p<.0 .039$, partial eta squared $=0.107$. Power to detect the effect was 1 .

- Wild card membership, age and gender: Wilks' $\lambda=0.870$, $F=3.288, p<0.047$, partial eta squared $=0.130$. Power to detect the effect was 1 .

From the above it is evident that a number of key variables influence the set of attachment factors, with the wild card membership, camp visited and the interaction between wild card membership, age and gender being the most influential. The fact that wild card membership explains the variance in the two factors of place attachment is not surprising, as one 
would expect members to have different levels of attachment than non-members. The factor camp visited also influences some patterning of the response on the dependent variable, again providing support for hypothesis 1 , that visitors differ in the levels of attachment they feel towards specific camps. Even though alone age and gender do not influence the variance in the two factors, it is interesting that the interaction between wild card membership, age and gender simultaneously explains a statistically significant amount of variance in the two attachment factors. The results from the MANOVA thus support the second hypothesis that certain variables influence the level of place attachment that visitors experience towards specific camps in the Kruger. The fact that wild card membership showed significant differences in place attachment in both the ANOVA and MANOVA results should encourage SANParks to find ways of boosting their membership sales. Yet, visitors will only become loyal to a park (and camp) if they are satisfied with the overall experience, which should provide more motivation for camp and park management to scrutinise the overall satisfaction levels of visitors, and create strategies to improve the scores of items with which visitors are not particularly happy.

\section{Discussion}

Bearing in mind that place attachment leads to more environmentally responsible visitors and increases visitor satisfaction, determining how to increase levels of place attachment has to be an important topic for Kruger National Park management. For this reason, the main purpose of this research study was to measure the extent to which visitors to the Tamboti and Satara camps in the Kruger National Park feel attached to these camps, while also determining whether differences exist between groups in terms of the level of attachment that they experience towards these camps. Finally, we established whether certain variables have a stronger influence on place attachment than other variables.

The results show that respondents did not have a particularly strong place attachment to Tamboti and Satara, even though some preferred the particular camps for their specific settings and facilities. It is expected that place attachment to the park in general will be higher as Hausmann et al. (2017) found in their study. Thus, attachment to the camps does not equate to attachment to the park, and visitors could be attached to the park in general, but not to specific camps. The Kruger National Park provides a variety of camps that may fulfil visitors' needs and some visitors might be attached to one camp, whereas others might be attached to another camp.

Our results offer possible answers to the questions raised by Barendse et al. (2016) in a previous article. In answer to their question on the link between individual and shared experiences in fostering place attachment, social bonding (shared experiences) scored the lowest mean of all four attachment dimensions in our results, contradicting the results of Hidalgo and Hernandez (2001) who determined that social attachments are stronger than setting attachments.
In response to their (Barendse et al. 2016) question relating to how attachment (SoP) experiences vary across nationalities of tourists, our results showed that South Africans have a higher level of continued attachment than international visitors.

As expected, wild card members showed a stronger place attachment than non-wild card members because it is obvious that loyal park visitors will be more attached to the camps. This confirms previous research studies showing that frequency of use is a significant predictor of place attachment (Lewicka 2005; Moore \& Scott 2003). Interestingly, those visitors with only a matric or high school qualification had the highest levels of place attachment, confirming the results of Lewicka (2005) and Rollera and De Piccoli (2010). The MANOVA tests showed a number of key variables influencing the set of attachment factors, with wild card membership, the camp visited and the interaction between wild card membership, age and gender being the most influential. This confirms the research of Poira, Reichel and Biran (2006) who found that the same place might have diverse meanings for diverse individuals.

A number of suggestions are made to increase visitors' attachment to Tamboti and Satara. Firstly, place attachment should be developed through long-term, frequent and positive experiences with the camps. Camp managers should ensure that visitors are satisfied when they depart from the camp to ensure future visitation. The more frequent the visits, the more likely visitors are to become attached (Lewicka 2005; Williams \& Patterson 1999). When taking the overall customer satisfaction scores for Tamboti and Satara into account, it is evident that two of the items with which visitors experienced the lowest satisfaction were 'nature experience' and 'caravan, camping and accommodation' at the camps. Camp management should thus show concerted efforts in trying to increase satisfaction with these items (SANParks 2019). Engagements with other people also affect place attachment (Eisenhauer, Krannich \& Blahna 2000). This is of particular importance given the low rating to place social bonding in our results. Camp management should encourage participation and social interaction in touristic activities in these camps to produce increased levels of attachment (Prayag \& Ryan 2012). In terms of place dependence, high scores imply that visitors are dependent on the resources of the camp to enjoy their specific tourist activities (Kyle et al. 2004). In our study, place dependence scored higher than the other three dimensions, even though the score was still neutral. Camp managers should thus endeavour to fulfil and meet tourists' real needs and services so that they can develop a sense of dependence on the camp (Cheng et al. 2013). Efforts should thus be made to improve tourist experiences by ensuring that visitors are satisfied with the infrastructure provided and intangible qualities (exoticness and reputation) (Prayag \& Ryan 2012).

Various authors have shown that place attachment leads to more environmentally responsible behaviour. At the same 
time, the higher visitors perceive the value of the camp experience, the more environmentally responsible they become. When tourists feel that they benefit from the experience, they are more likely to identify more strongly with the environment. This, in turn, will stimulate their sensitivity towards and concern for the environment, which will shape their environmentally responsible behaviour. It is thus suggested that camp management should increase the satisfaction with the camp experience in order to promote environmentally responsible behaviour in the camp, decreasing the damage to the environment (Chiu, Lee \& Chen 2014). This could be attained by ensuring that the camp shows proof of good management, support for biodiversity and reinforcement of sustainable and responsible consumption, which are likely to be valued by visitors (Ramkissoon \& Mavondo 2014). If the tourists see the camp's commitment to conservation, it is likely to encourage them to show environmentally responsible behaviour (Lee 2011).

The theoretical contribution of this article lies in the fact that it adds to the debate on whether place attachment should be seen as a multidimensional or bi-dimensional construct. As opposed to previous studies indicating four dimensions (Devine-Wright \& Clayton 2010; Ramkissoon et al. 2013), our results only showed two, with the one dimension, labelled interrupted attachment, showing very low levels of attachment.

This article is not without limitations. The results of this study cannot be generalised to all Kruger visitors as the sample was non-random. Future research should look at how place attachment experiences differ for each camp and each national park (based on feedback from visitors) and whether place attachment experiences should be taken into account in the design, establishment and management of protected areas (Barendse et al. 2016). Furthermore, Hausmann et al. (2017) mentioned the lack of understanding about how biodiversity, and experiences related to biodiversity, influence tourists' place attachment when visiting protected areas. Future research should look into this.

\section{Conclusion}

The purpose of this study was to measure the extent to which visitors are attached to the Tamboti and Satara camps in the Kruger National Park. In addition, we assessed whether visitors' levels of place attachment differ. Finally, we established whether certain variables have a stronger influence on levels of place attachment than other variables. The research identifies two factors of place attachment, confirming the research of Cheng et al. (2013) and contradicting the results of Ramkissoon et al. (2013a). The research also finds that visitors to Tamboti and Satara have neutral levels of attachment to the camps. Furthermore, ANOVA results show that levels of attachment between visitors differ in terms of nationality, wild card membership, level of education, number of visits and the camp visited. The MANOVA results indicate that the main variables that have an influence on place attachment are wild card membership, the camp visited and the interaction between wild card membership, age and gender.

Our results confirm the results of Hausmann et al. (2017) showing differences between nationalities. The results also confirm the results of Moore and Scott (2003), who showed differences in place attachment in terms of frequency of visits. Contrary to research by Ednie et al. (2010), our research did not show differences in levels of place attachment in terms of the group that the respondents travel with. Also, Kyle et al. (2004) found no significant difference in terms of level of education, whereas our results show significant differences.

This article contributes to the current literature regarding place attachment, and specifically place attachment in the context of camps in the Kruger National Park. This is the first time that place attachment is measured in the context of camps within parks. In doing so, sensible management conclusions have been reached.

In conclusion, place attachment (sense of place) is a vital feature of conservation from both legal and conceptual viewpoints (Barendse et al. 2016). As such, results such as ours could be used to inform park management plans and conservation action. The study responds to a call from Barendse et al. (2016) who suggested that place attachment should be accounted for from both social and natural lenses to enable debates of the 'desired future conditions' of conservation areas from both social and ecological viewpoints (Williams \& Stewart 1998). Our results provide the social lens and viewpoints and thus stimulate communication and interdisciplinary learning not only between natural and social scientists but also between management, science and all stakeholders (Chapin III \& Knapp 2015).

\section{Acknowledgements}

The authors would like to thank the Tourism Development and Marketing Division of South African National Parks for their support of the project.

\section{Competing interests}

The authors declare that they have no conflicts of interest.

\section{Authors' contributions}

A.D. was the lead author of this article. The remainder of the authors all contributed in reviewing the article, developing the measurement instrument and collecting the data.

\section{Funding information}

This work is based on the research supported in part by the National Research Foundation of South Africa (Grant Number 114916). 


\section{Data availability statement}

Data are available upon request from the corresponding author.

\section{Disclaimer}

The views and opinions expressed in this article are those of the authors and do not necessarily reflect the official policy or position of any affiliated agency of the authors.

\section{References}

Altman, L. \& Low, S., 1992, Place attachment, Plenum Press, New York.

Ament, J., Moore, C., Herbst, M. \& Cumming, G., 2017, 'Cultural ecosystem services in protected areas: Understanding bundles, trade-offs, and synergies', Conservation Letters 10(4), 440-450. https://doi.org/10.1111/conl.12283

Barendse, J., Roux, D., Erfmann, W., Baard, J., Kraaij, T. \& Nieuwoudt, C., 2016, 'View shed and sense of place as conservation features: A case study and research agenda for South Africa's national parks', Koedoe 58(1), a1357. https://doi. org/10.4102/koedoe.v58i1.1357

Bowlby, J., 1969, Attachment and loss: Attachment, vol. 1, Basic Books, New York.

Brown, B., Perkins, D. \& Brown, G., 2003, 'Place attachment in a revitalizing Psychology 23, 259-271. https://doi.org/10.1016/S0272-4944(02)00117-2

Budruk, M., Thomas, H. \& Tyrrell, T., 2009, 'Urban green spaces: Place attachment and environmental attitudes in India', Society and Natural Resource 22, 824-839. https://doi.org/10.1080/08941920802628515

Cass, N. \& Walker, G., 2009, 'Emotion and rationality: The characterisation and evaluation of opposition to renewable energy projects', Emotion, Space and Society 2(1), 62-69. https://doi.org/10.1016/j.emospa.2009.05.006

Chan, K., Satterfield, T. \& Goldstein, J., 2012, 'Rethinking ecosystem services to better address and navigate cultural values', Ecological Economics 74, 8-18. https://doi. org/10.1016/j.ecolecon.2011.11.011

Chapin, III, F.S. \& Knapp, C.N., 2015, 'Sense of place: A process for identifying and negotiating potentially contested visions of sustainability', Environmental Science negotiating potentially contested visions of sustainability', Enviro
\& Policy 53, 38-46. https://doi.org/10.1016/j.envsci.2015.04.012

Chen, N., Dwyer, L. \& Firth, T., 2014, 'Conceptualization and measurement of dimensionality of place attachment', Tourism Analysis 19, 323-338. https://doi.or $\mathrm{g} / 10.3727 / 108354214 \times 14029467968529$

Cheng, T., Wu, H. \& Huang, L., 2013, 'The influence of place attachment on the relationship between destination attractiveness and environmentally responsible behavior for island tourism in Penghu, Taiwan', Journal of Sustainable Tourism 21(8), 1166-1187. https://doi.org/10.1080/09669582.2014.965177

Chiu, Y., Lee, W. \& Chen, T., 2014, 'Environmentally responsible behaviour in ecotourism: Antecedents and implications', Tourism Management 40, 321-329. https://doi.org/10.1016/j.tourman.2013.06.013

Clayton, S. \& Opotow, S., 2003, 'Introduction: Identity and the natural environment', in S. Clayton \& S. Opotow (eds.), Identity and the natural environment: The psychological significance of nature, pp. 1-24, MIT Press, Cambridge, MA.

Cross, J., 2001, 'What is "sense of place"?', paper presented at The Twelfth Headwaters Conference, Western State College, November 2-4.

Devine-Wright, P. \& Clayton, S., 2010, 'Introduction to the special issue: Place, identity and environmental behavior', Journal of Environmental Psychology 30, 267-270. https://doi.org/10.1016/S0272-4944(10)00078-2

Dredge, D., 2010, 'Place change and tourism development conflict: Evaluating public interest', Tourism Management 31(1), 104-112. https://doi.org/10.1016/j. tourman.2009.01.004

Ednie, A.J., Daigle, J.J. \& Leahy, J.E., 2010, 'The development of recreation place attachment on the Maine Coast: User characteristics and reasons for visiting', Journal of Park and Recreation Administration 28(1), 36-51.

Eisenhauer, B.W., R.S. Krannich \& D.J. Blahna., 2000, 'Attachment to special places on public lands: An analysis of activities, reasons for attachments, and community connections', Society and Natural Resources 13(5), 421-441. https://doi. org/10.1080/089419200403848

Gosling, E. \& Williams, K., 2010, 'Connectedness to nature, place attachment and conservation behavior: Testing connectedness theory among farmers', Journal of conservation behavior: Testing connectedness theory among farmers', Journal of
Environmental Psychology 30(3), 298-304. https://doi.org/10.1016/j.jenvp.2010. 01.005

Hair, J.F., Black, W.C., Babin, B.J. \& Anderson, R.E., 2014, Multivariate data analysis, Pearson Education Limited, Essex.

Halpenny, E., 2010, 'Pro-environmental behaviours and park visitors: The effect of place attachment', Journal of Environmental Psychology 30, 409-421. https://doi. org/10.1016/j.jenvp.2010.04.006

Halpenny, E.A., 2006, 'Environmental behaviour, place attachment and park visitation A case study of visitors to Point Pele National Park', Unpublished doctoral dissertation, University of Waterloo, Ontario, Canada.

Hammitt, W., Backlund, E. \& Bixler, R., 2006, 'Place bonding for recreational places: Conceptual and empirical development', Leisure Studies 25(1), 17-41. https://doi. org/10.1080/02614360500098100
Harris, B., Brown, B. \& Werner, M., 1996, 'Privacy regulation and place attachment: Predicting attachments to a student family housing facility', Journal of Predicting attachments to a student family housing facility', Journal of
Environmental Psychology 16, 287-301. https://doi.org/10.1006/jevp.1996.0025

Hartig, T., Book, A., Garvill, J., Olsson, T. \& Garling, T., 1996, 'Environmental influences on psychological restoration', Scandinavian Journal of Psychology 37(4), 378-393. https://doi.org/10.1111/j.1467-9450.1996.tb00670.x

Hausmann, A., Slotow, R., Fraser, I. \& Di Minin, E., 2017, 'Ecotourism marketing alternative to charismatic megafauna can also support biodiversity conservation', Animal Conservation 20, 91-100. https://doi.org/10.1111/acv.12292

Hidalgo, M. \& Hernandez, B., 2001, 'Place attachment: Conceptual and empirical questions', Journal of Environmental Psychology 21(3), 273-281. https://doi.org/ 10.1006/jevp.2001.0221

Hinds, J. \& Sparks, P., 2008, 'Engaging with the natural environment: The role of affective connection and identity', Journal of Environmental Psychology 28, 109-120. https://doi.org/10.1016/j.jenvp.2007.11.001

Hwang, S., Lee, C. \& Chen, H., 2005, 'The relationship among tourists' involvement place attachment and interpretation satisfaction in Taiwan's national parks', Tourism Management 26(2), 143-156. https://doi.org/10.1016/j.tourman Tourism Manad

Jorgensen, B. \& Stedman, R., 2001, 'Sense of place as an attitude: Lakeshore owners' attitudes toward their properties', Journal of Environmental Psychology 21, 233-248. https://doi.org/10.1006/jevp.2001.0226

Kals, E. \& Maes, J., 2002, 'Sustainable development and emotions', in P. Schmuck \& W. Schultz (eds.), Psychology of sustainable development, pp. 97-122, Kluwer, Norwell, MA.

Kals, E., Shumaker, D. \& Montada, L., 1999, 'Emotional affinity toward nature as a motivational basis to protect nature', Environment and Behaviour 31, 178-202. https://doi.org/10.1177/00139169921972056

Klenosky, D.B., LeBlanc, C.L., Vogt, C.A. \& Schroeder, H.W., 2007, 'Factors that attract and repel visitation to urban recreation sites: A framework for research', paper presented at the 2007 Northeastern Recreation Research Symposium. Bolton Landing, New York.

Kruger, M., Viljoen, A. \& Saayman, M., 2017, 'Who visits the Kruger National Park, and why? Identifying target markets', Journal of Travel \& Tourism Marketing 34(3), 312-340. https://doi.org/10.1080/10548408.2016.1156618

Kyle, G., Absher, J. \& Graefe, A., 2003, 'The moderating role of place attachment on the relationship between attitudes toward fees and spending preference', Leisure Sciences 25(1), 33-50.

Kyle, G., Graefe, A. \& Manning, R., 2004a, 'Attached Recreationists ... Who are they?', Journal of Park and Recreation Administration 22(2), 65-84.

Kyle, G., Graefe, A. \& Manning, R., 2005, 'Testing the dimensionality of place attachment in recreational settings', Environment and Behavior 37(2), 153-177. https://doi.org/10.1177/0013916504269654

Kyle, G., Graefe, A., Manning, R. \& Bacon, J., 2004b, 'Effects of place attachment on users' perceptions of social and environmental conditions in a natural Setting', Journal of Environmental Psychology 24(2), 213-225. https://doi.org/10.1016/j. jenvp.2003.12.006

Lee, T., 2011, 'How recreation involvement, place attachment and conservation commitment affect environmentally responsible behavior', Journal of Sustainable Tourism 19(7), 895-915. https://doi.org/10.1080/09669582.2011.570345

Lewicka, M., 2005, 'Ways to make people active: The role of place attachment, cultural capital, and neighbourhood ties', Journal of Environmental Psychology 25, 381-395. https://doi.org/10.1016/j.jenvp.2005.10.004

Lewicka, M., 2008, 'Place attachment, place identity, and place memory: Restoring the forgotten city past', Journal of Environmental Psychology 28, 209-231. https:// doi.org/10.1016/j.jenvp.2008.02.001

Lewicka, M., 2010, 'What makes neighborhood different from home and city? Effects of place scale on place attachment', Journal of Environmental Psychology 30 35-51. https://doi.org/10.1016/j.jenvp.2009.05.004

Low, S.M. \& Altman, I., 1992, 'Place attachment: A conceptual inquiry', in I. Altman \& S.M. Low (eds.), Place attachment, pp. 1-12, Plenum Press, New York.

McLeod, B. \& Busser, J., 2012, 'Second-home ownership and place attachment: Drivers of visitation, word-of-mouth promotion, and hosting', Tourism Analysis Drivers of visitation, word-of-mouth promotion, and hosting', Tourism
17(5), 601-616. https://doi.org/10.3727/108354212X13485873913886

Millennium Ecosystem Assessment (MEA), 2005, Ecosystems and human well-being: Synthesis, Island Press, Washington, DC.

Moore, R. \& Graefe, A., 1994, 'Attachments to recreation settings', Leisure Sciences 16 , 17-31. https://doi.org/10.1080/01490409409513214

Moore, R.L. \& D. Scott., 2003, 'Place attachment and context: Comparing a park and a trail within', Forest Science 49(6), 877-884.

$\mathrm{Ng}$, S., Kam, P. \& Pong, R., 2005, 'People living in ageing buildings: Their quality of life and sense of belonging', Journal of Environmental Psychology 25, 347-360. and sense of belonging', Journal of Environn
$\mathrm{https}: / /$ doi.org/10.1016/j.jenvp.2005.08.005

Nunnally, J.C., 1978, Psychometric theory, McGraw-Hill, New York.

Perkins, D. \& Long, A., 2002, 'Neighbourhood sense of community and social capital: A multi-level analysis', in A. Fischer, C. Sonn \& B. Bishop (eds.), Psychological sense of community: Research, applications and implications, pp. 291-318, Plenum Press, New York.

Poira, Y., Butler, R. \& Airey, D., 2001, 'Tourism sub-groups: Do they exist?', Tourism Today 1(1), 14-22.

Prayag, G. \& Ryan, D., 2012, 'Antecedents of tourists' loyalty to Mauritius: The role and influence of destination image, place attachment, personal involvement, and satisfaction', Journal of Travel Research 51(3), 342-356. https://doi.org/10.1177/ 0047287511410321 
Pretty, G., Chipuer, H. \& Bramston, P., 2003, 'Sense of place amongst adolescents and adults in two rural Australian towns: The discriminating features of place attachment, sense of community and place dependence in relation to place identity', Journal of Environmental Psychology 23, 273-287. https://doi. org/10.1016/S0272-4944(02)00079-8

Prohansky, H., 1978, 'The city and self-identity', Environment and Behaviour 10, 147-169. https://doi.org/10.1177/0013916578102002

Ramkissoon, H. \& Mavondo, F., 2014, 'Proenvironmental behavior: The link between place attachment and place satisfaction', Tourism Analysis 19, 673-688. https:// doi.org/10.3727/108354214X14146846679286

Ramkissoon, H., Smith, L. \& Weiler, B., 2013a, 'Relationships between place attachment, place satisfaction and pro-environmental behaviour in an Australian nationa park', Journal of Sustainable Tourism 21(3), 434-457. https://doi.org/10.1080/09 669582.2012.708042

Ramkissoon, H., Smith, L. \& Weiler, B., 2013b, 'Testing the dimensionality of place attachment and its relationships with place satisfaction and pro-environmental behaviours: A structural equation modelling approach', Tourism Management 36 , 552-566. https://doi.org/10.1016/j.tourman.2012.09.003

Ramkissoon, H., Weiler, B. \& Smith, L., 2012, 'Place attachment and pro-environmental behavior in national parks: The development of a conceptual framework', Journal
of Sustainable Tourism 20(2), 257-276. https://doi.org/10.1080/09669582.2011. of Sustainab
602194

Reimann, M., Lamp, M. \& Palang, H., 2011, 'Tourism impacts and local communities in Estonian national parks', Scandinavian Journal of Hospitality \& Tourism 11(1) 87-99. https://doi.org/10.1080/15022250.2011.638206

Rollero, C. \& De Piccoli, N., 2010, 'Place attachment, identification and environment perception: An empirical study', Journal of Environmental Psychology 30, 196-205. https://doi.org/10.1016/j.jenvp.2009.12.003

SANParks, 2019, KNP and Satara and Tamboti customer satisfaction May to July 2017

Scannell, L. \& Gifford, R., 2010, 'The relations between natural and civic place attachment and pro-environmental behavior', Journal of Environmental Psychology 30, 289-297. https://doi.org/10.1016/j.jenvp.2010.01.010

Schultz, P., 2000, 'Empathizing with nature: The effects of perspective taking on concern for environmental issues', Journal of Social Issues 56(3), 391-406. https:// doi.org/10.1111/0022-4537.00174

Stedman, R., 2002, 'Toward a social psychology of place: Predicting behaviour from place-based cognitions, attitudes, and identity', Environment and Behaviour 34, 561-581. https://doi.org/10.1177/0013916502034005001
Stokols, D. \& Shumacker, S., 1981, 'People in places: A transactional view of Settings', in J. Harvey (ed.), Cognition, social behavior, and the environment, pp. 441e448, Erlbaum, Hillsdale, NJ.

Tonge, J., Ryan, M., Moore, S. \& Beckley, L., 2015, 'The effect of place attachment on pro-environment behavioral intentions of visitors to coastal natural area tourist destinations', Journal of Travel Research 54(6), 730-743. https://doi. org/10.1177/0047287514533010

Tsai, S., 2012, 'Place attachment and tourism marketing: Investigating international tourists in Singapore', International Journal of Tourism Research 14(2), 139-152. https://doi.org/10.1002/jtr.842

Tuan, Y., 1977, Space and place: The perspective of experience, University of Minnesota Press, Minneapolis, MN.

Twigger-Ross, C. \& Uzzell, D., 1996, 'Place and identity processes', Journal of Environmental Psychology 16(3), 205-220. https://doi.org/10.1006/jevp.1996. 0017

Vaske, J. \& Kobrin, K., 2001, 'Place attachment and environmentally responsible Behavior', The Journal of Environmental Education 32(4), 16-21. https://doi. Behavior', The Journal of Environ
org/10.1080/00958960109598658

Vining, J., 1992, 'Environmental emotions and decisions', Environment and Behavior 24(1), 3-34. https://doi.org/10.1177/0013916592241001

Walker, G. \& Chapman, R., 2003, 'Thinking like a park: The effects of sense of place, perspective-taking, and empathy on pro-environment intentions', Journal of Park and Recreation Administration 21(4), 71-86.

Williams, D. \& Patterson, M., 1999, 'Environmental psychology: Mapping landscape meanings for ecosystem management', in H.K. Cordell \& J.C. Bergstrom (eds.) Integrating social sciences and ecosystem management: Human dimensions in assessment, policy and management, pp. 141-160, Sagamore Press, Champaign, IL.

Williams, D., Patterson, M., Roggenbuck, J. \& Watson, A., 1992, 'Beyond the commodity metaphor: Examining emotional and symbolic attachment to place', Leisure Sciences 14, 29-46. https://doi.org/10.1080/01490409209513155

Williams, D. \& Stewart, S., 1998, 'Sense of place: An elusive concept that is finding a home in ecosystem management', Journal of Forestry 96, 18-23.

Williams, D. \& Vaske, J., 2003, 'The measurement of place attachment: Validity and generalizability of a psychometric approach', Forest Science 49(6), 830-840.

Yuksel, A., Yuksel, F. \& Bilim, Y., 2010, 'Destination attachment: Effects on customer satisfaction and cognitive, affective and connative loyalty', Tourism Management 31(2), 274-284. https://doi.org/10.1016/j.tourman.2009.03.007 